\title{
Distribution and diversity of oligotrich and choreotrich ciliates across an environmental gradient in a large temperate estuary
}

\author{
Maiko Tamura ${ }^{1,4}$, Laura A. Katz ${ }^{1,2}$, George B. McManus ${ }^{3, *}$ \\ ${ }^{1}$ Department of Biological Sciences, Smith College, Northampton, Massachusetts 01063, USA \\ ${ }^{2}$ Program in Organismic and Evolutionary Biology, University of Massachusetts, Amherst, Massachusetts 01003, USA \\ ${ }^{3}$ Department of Marine Sciences, University of Connecticut, Groton, Connecticut 06340, USA \\ ${ }^{4}$ Present address: Evolutionary Systems Biology Unit, Okinawa Institution of Science and Technology, 1919-1 Tancha, \\ Onna-son, Kunigami, Okinawa 904-0412, Japan
}

\begin{abstract}
Using a combination of clone library and DGGE analyses, we assessed the diversity of coastal planktonic ciliates from the oligotrich and choreotrich clades across environmental gradients in Long Island Sound, USA. We sampled fresh and saline, as well as stratified and well-mixed, waters and found that these ciliate assemblages consist of a few common haplotypes and numerous rare haplotypes. Rarefaction estimates of total richness indicated that our survey did not cover the full diversity of the samples, suggesting that there may be many more haplotypes present in the Sound than predicted by previous microscopic surveys. We also found that haplotype richness varied on small spatial scales $(<1 \mathrm{~km})$ and that differences in community composition among samples are not readily attributable to commonly measured environmental factors. This result suggests that the driving forces behind these differences are more complex than the abiotic measures captured here. In common with other studies, we found that most of the haplotypes we observed had not been identified previously and posted on public genetic databases.
\end{abstract}

KEY WORDS: Oligotrichia · Choreotrichia $\cdot$ Coastal ciliate $\cdot$ Long Island Sound · Haplotype diversity · Microbial assemblage

Resale or republication not permitted without written consent of the publisher

\section{INTRODUCTION}

Numerous studies assessing microbial distributions based on morphology led to the historic view that microbes are not dispersal-limited (reviewed in Finlay 2002, Foissner 2006). Molecular techniques allow us to examine microbial dispersal without the need to make morphological distinctions among closely related microbes and such studies do indicate that dispersal of microbial forms can be global (e.g. Darling et al. 2000, Cermeno \& Falkowski 2009). However, despite the evidence that microbes are widely dispersed, only a few studies examine the relationship between diversity and distribution of individual taxa in relation to environmental factors, especially for eukaryotic microbes.
Furthermore, the spatial scales on which microbial eukaryote communities vary or are correlated with environmental factors have not been identified.

Some spatial patterns of microbial assemblages have been reported in various environments and across varying scales. For instance, Countway et al. (2007) demonstrated the differences in protist community structure and diversity between the euphotic zone and the deep sea. Using a fingerprinting technique, DGGE, comparison of protistan assemblages within microhabitats (seawater, slush and ice) in Antarctica revealed that the same environments have a similar microbial composition (Gast et al. 2004). Doherty et al. (2007) assessed planktonic ciliate diversity in coastal Atlantic waters, showing that on large scales (hundreds of kilo- 
meters) each sample contained a distinct assemblage of rare and abundant haplotypes. Community profiling of marine prokaryotes at the millimeter scale has also indicated significant variation in richness (Long \& Azam 2001); the same study also showed distinct patterns of bacterial richness and patchiness during and subsequent to a dinoflagellate bloom. Using automated ribosomal intergenic spacer analysis (ARISA), Hewson et al. (2006) found that bacterial assemblages were highly similar when sampled on kilometer scales but that similarity dropped off between 2 and $50 \mathrm{~km}$, suggesting that physical mixing of assemblages ensures relative uniformity on smaller scales but beyond around $10 \mathrm{~km}$ biological interactions or habitat selection create distinct assemblages. For ciliates, a few microscopy-based studies exist that examined the spatial scales over which abundance varies. Montagnes et al. (1999), for example, showed patchiness of planktonic ciliates that was associated with fronts and other oceanographic features at kilometer or greater scales in the horizontal and meter scales in the vertical. Bulit et al. (2004) examined distributions of a single ciliate morphospecies in a tropical coastal lagoon and found seasonally-varying patchiness on scales of tens of meters.

One consistent finding that has emerged from microbial diversity studies using molecular techniques is the presence of a large number of rare taxa - the 'rare biosphere' (e.g. Sogin et al. 2006, Caron \& Countway 2009). In numerous published studies of marine systems, rarefaction curves (the number of distinct taxa encountered in repeated samplings as a function of the total number of clones sampled) often do not reach an asymptote, indicating that many taxa have yet to be found (Countway et al. 2005, Sogin et al. 2006, Countway et al. 2007, Doherty et al. 2007, Caron 2009). Thus, microbial assemblages can be described with long-tail rank abundance curves composed of a small number of abundant 'core taxa' and an extremely large number of rare taxa (Pedros-Alio 2006, Sogin et al. 2006, Countway et al. 2007, Caron 2009). This 'rare biosphere' may represent a bank of organisms that could become abundant under different environmental conditions (Countway et al. 2005, Sogin et al. 2006, Brown et al. 2009).

This paper focuses on 2 groups of ciliates, the Spirotrichea subclasses Oligotrichia and Choreotrichia (Lynn 2008), that are key members of marine planktonic food webs where they serve as important grazers of nano- and picoplankton (Pierce \& Turner 1993, Calbet \& Saiz 2005) as well as a food source for larger zooplankton and larval fish (Stoecker \& Govoni 1984, Gifford 1991). Many morphologically-based studies of factors underlying community composition in these 2 groups have been completed, especially for the tintinnids, a species-rich order within the Choreotrichia (e.g.
Sime-Ngando et al. 1992, Thompson \& Alder 2005, Dolan et al. 2007, Dolan et al. 2009, Lei et al. 2009, Sitran et al. 2009).

More recently, our laboratories have used groupand species-specific primers to document distributions of these ciliates in coastal waters (Costas et al. 2007, Doherty et al. 2007, Doherty et al. 2010a,b). For example, we constructed clone libraries of planktonic ciliates from stations separated by hundreds of kilometers (northwest Atlantic shelf; Doherty et al. 2007) and by hundreds of meters in the same area as the current study (Doherty et al. 2010a). In both cases, we found distinct assemblages at each station with the exception of a few abundant overlapping haplotypes. In the finer scale study, we found evidence that the assemblages could be clustered based on proximity to the Connecticut River outflow plume (Doherty et al. 2010a).

The present study evaluates distributions at the mesoscale (kilometers to tens of kilometers) and relates assemblage composition to larger oceanographic features of Long Island Sound (LIS). We assess the diversity and spatial distribution pattern of oligotrich and choreotrich ciliates using a combination of clone library and DGGE analyses based on partial small subunit ribosomal DNA (SSU rDNA) sequences. Because some of the stations we sampled were in the same area as Doherty et al. (2010a), we also address how assemblages of coastal ciliates change across both space and time. We hypothesized that (1) changes in assemblage composition would be correlated with distance and such features as density stratification and salinity fronts and (2) many more rare haplotypes would be present than common ones, as observed in prokaryote assemblages.

\section{MATERIALS AND METHODS}

Station locations and sample collection. On 13 August 2008, we sampled 6 stations in LIS. The stations represented a range of variation in depth, salinity, and vertical stratification (Fig. 1, Table 1). Stn 1 ('river') was approximately $2 \mathrm{~km}$ upstream from the mouth of the Connecticut River. Stn 2 ('plume') was in the lower salinity region of the river's outflow plume. Stn 3 ('near_Plume') was close to the plume but outside of the visible plume edge front. Stn 4 ('offshore') was located in the middle of the Sound. Stns 5 ('shore') and 6 ('front') were located on the south shore of the Sound in a region close to open shelf waters where tidal mixing can produce strong horizontal gradients in the degree of density stratification (Bowman et al. 1981). Thus, our stations ranged from riverine (surface salinity $<1$ ) to coastal (surface salinity $>26$ ), with a maximum spatial separation of $23 \mathrm{~km}$. 


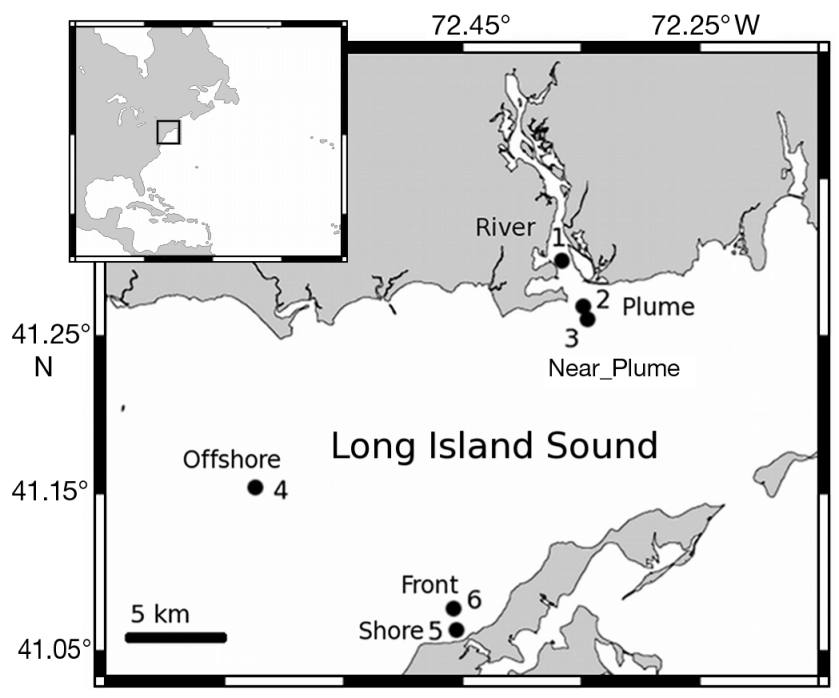

Fig. 1. Location of sampling stations ( $)$ in Long Island Sound, a large estuary on the northeast coast of North America. Scale bar $=5 \mathrm{~km}$

At Stns 1, 4, 5, and 6 water samples were collected at the surface with a bucket and below the pycnocline with a Niskin bottle. Because Stns 2 and 3 were shallow and in the strong current sampling the same location reliably at depth was not possible; only surface samples were taken. At each station, temperature and salinity were measured with a SeaBird CTD for the purpose of calculating density profiles. These data were smoothed by binning at $0.1 \mathrm{~m}$ intervals.

DNA extraction. A 21 sample was filtered onto $3.0 \mu \mathrm{m}$ pore size cellulose nitrate filters for each station and depth. The filters were placed in $0.75 \mathrm{ml}$ lysis buffer, and DNA was subsequently extracted using Zymo DNA kit D6005 (Zymo Research).

PCR amplification and clone library construction. Partial SSU rDNA for clone library construction was amplified with Phusion DNA polymerase (New England BioLabs). Primers used in this study, including those for DGGE (see below), are given in Table 2. We used 2 oligotrich-/choreotrich-specific SSU rDNA primers (OCSP-A and OCSP-B) as described in Doherty et al. (2007). We thus generated 2 separate clone libraries from samples from most stations. OCSPA libraries were created from all samples except the offshore deep sample, which proved difficult to amplify; OCSP-B libraries were made from surface samples only. Target regions were amplified with

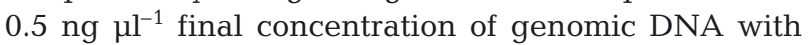
touchdown PCR under the following conditions: initial denaturing temperature $98^{\circ} \mathrm{C}$ for $3 \mathrm{~min}, 5$ cycles of $98^{\circ} \mathrm{C}$ for $30 \mathrm{~s}, 72^{\circ} \mathrm{C}$ for $30 \mathrm{~s}, 72^{\circ} \mathrm{C}$ for $1 \mathrm{~min}$, followed by a decrease in annealing temperature of $1^{\circ} \mathrm{C}$ for every cycle down to $68^{\circ} \mathrm{C}$. This procedure was followed by 22 additional cycles with annealing temperature at $68^{\circ} \mathrm{C}$

Table 1. Station locations and environmental data. Sampling began on the falling tide (high water was at 08:00 h) because the ebb current sharpens the salinity front between river plume and coastal waters

\begin{tabular}{|c|c|c|c|c|c|c|c|c|}
\hline Stn & Description & $\begin{array}{l}\text { Depth } \\
\text { (m) }\end{array}$ & Latitude & Longitude & $\begin{array}{l}\text { Local time } \\
\text { (h) }\end{array}$ & $\begin{array}{c}\text { Temperature } \\
\left({ }^{\circ} \mathrm{C}\right)\end{array}$ & $\begin{array}{l}\text { Salinity } \\
\text { (PSU) }\end{array}$ & $\begin{array}{l}\text { Oxygen } \\
\left(\mathrm{mg} \mathrm{l}^{-1}\right)\end{array}$ \\
\hline \multirow[t]{2}{*}{1} & River-S & Surface & $41^{\circ} 17.2^{\prime} \mathrm{N}$ & $72^{\circ} 20.8^{\prime} \mathrm{W}$ & $10: 40$ & 21.3 & 0.1 & 8.9 \\
\hline & River-D & 6 & & & & 20.2 & 27.7 & 7.7 \\
\hline 2 & Plume-S & Surface & $41^{\circ} 15.7^{\prime} \mathrm{N}$ & $72^{\circ} 20.1^{\prime} \mathrm{W}$ & $11: 10$ & 21.2 & 6.4 & 8.5 \\
\hline 3 & Near_Plume-S & Surface & $41^{\circ} 15.4^{\prime} \mathrm{N}$ & $72^{\circ} 19.7^{\prime} \mathrm{W}$ & $11: 30$ & 21.1 & 24.0 & 7.7 \\
\hline \multirow[t]{2}{*}{4} & Offshore-S & Surface & $41^{\circ} 9.5^{\prime} \mathrm{N}$ & $72^{\circ} 33.6^{\prime} \mathrm{W}$ & $13: 00$ & 22.5 & 26.1 & 7.4 \\
\hline & Offshore-D & 12 & & & & 20.9 & 28.1 & 7.6 \\
\hline \multirow[t]{2}{*}{5} & Shore-S & Surface & $41^{\circ} 5.4^{\prime} \mathrm{N}$ & $72^{\circ} 25.3^{\prime} \mathrm{W}$ & $14: 00$ & 22.9 & 26.1 & 7.4 \\
\hline & Shore-D & 3.5 & & & & 22.0 & 27.5 & 7.4 \\
\hline \multirow[t]{2}{*}{6} & Front-S & Surface & $41^{\circ} 6.1^{\prime} \mathrm{N}$ & $72^{\circ} 25.2^{\prime} \mathrm{W}$ & $14: 20$ & 23.2 & 26.9 & 7.3 \\
\hline & Front-D & 17 & & & & 21.2 & 28.1 & 7.5 \\
\hline
\end{tabular}

Table 2. Oligotrichia- and Choreotrichia-specific primer sequences used in present study. Primers $152+\mathrm{F}$ and $353 \mathrm{rGC}$ were used for PCR-DGGE

\begin{tabular}{|lllc|}
\hline Primer set & Primer name & Sequence & Length \\
\hline OCSP-A & 152+(for) & 5'-TTA CAT GGA TAA CCG TGG TAA TTC-3' & 376 \\
& $528-($ rev) & 5'-CCC GGC CCG TTA TTT CTT GT-3' & \\
OCSP-B & 1199+(for) & 5'-GCC GAC TCG GGA TCG GGG GC-3' & 566 \\
DGGE (GC clamp) & 1765-(rev) & 5'-CCC CAK CAC GAC DCM TAT TGC TG-3' & \\
& & 5'-CGC CCG CCG CGC CCC GCG CCC GTC CCG-3' & 201 \\
& & 5'-CCG CCC CCG CCC CAT CGA AAG CTG ATG GG-3' & \\
\hline
\end{tabular}


and a 10 min final extension at $72^{\circ} \mathrm{C}$. For cloning, we used the Zero Blunt TOPO PCR Cloning Kit (Invitrogen, cat. no. K2800-20). Colonies were picked and miniprepped using the PureLink Plasmid Purification System (Invitrogen, cat. no. 12263-018). DNA was sequenced either in an ABI 3100 automated sequencer at the Penn State University Nucleic Acid Facility in University Park, Pennsylvania or an ABI 377 automated sequencer at Smith College.

Sequence assembly, genealogical analyses and statistical analyses of clone libraries. We removed sequences that were $<70 \%$ of the total length of our target region. Sequences were then assembled at a $99 \%$ similarity cutoff using SeqMan (DNAStar). Haplotypes, which we are using as operational taxonomic units (OTUs), were checked for identity with published sequences using the basic local alignment search tool (BLAST) (Altschul et al. 1997) at the National Center for Biotechnology Information (NCBI), then aligned with published sequences of Oligotrichia and Choreotrichia morphospecies obtained by searching GenBank. We used the CLUSTAL W algorithm as implemented in MegAlign to align our sequences with the published sequences and then edited alignments by eye in MacClade v4.08. To identify potential PCR artifacts such as chimeras, we used the programs Chimera (Smith 1992, Posada \& Crandall 2001, Posada 2002), GENECOV (Padidam et al. 1999) and MaxChi (Smith 1992, Posada \& Crandall 2001) in RDP v2.0 (Martin et al. 2005) and the online software GARD (www. datamonkey.org/GARD/).

We used 3 indices to compare haplotype diversity among stations: rarefaction curves (Sobs MaoTau), Shannon's index $\left(H^{\prime}\right)$, and Chao1. These indices were calculated using EstimateS version 8.0 with 100 randomized samplings without replacement (Colwell 2006). Because of its estimated coefficient of variation $>0.5$, Chao1 was computed using the classic instead of the bias-corrected method for all samples except Stn 4 (offshore, surface; primer set OCSP-A) and Stns 5 (shore, surface; primer set OCSP-B) and 6 (front, surface; primer set OCSP-B).

To compare community assemblages among samples, we used the computer program UniFrac, which is able to compare many environments simultaneously using hierarchical clustering analysis and principal coordinate analysis (PCoA) (Lozupone \& Knight 2005, Lozupone et al. 2006). UniFrac measures the distance between 2 communities as the total branch length in the given tree that leads to descendants of members of either community but not both (Lozupone \& Knight 2005). These analyses were carried out on both RAxML and star trees, using text files with haplotype abundance levels mapped to environmental samples as input. RAxML trees were constructed on the Cyber- infrastructure for Phylogenetic Research (CIPRES) portal v1.15 (www.phylo.org/sub_sections/portal/). We made comparisons using both abundance-weighted and unweighted (presence/absence) branch length normalization. We also clustered haplotypes using the unweighted pair group method with arithmetric mean (UPGMA) hierarchical clustering algorithm. The robustness of the UPGMA clusters was tested with jacknife analysis, a non-parametric method, based on 100 randomized sub-samples.

PCR-DGGE analyses. To create the amplicons for DGGE, we used the OCSP-A forward primer from Doherty et al. (2007) and designed a reverse primer with a GC clamp added to the 5' end (Table 2, primer 353rGC). Using this primer set, target regions were amplified with $0.5 \mathrm{ng}^{-1}$ final concentration of genomic DNA under the following PCR conditions: initial denaturing temperature $98^{\circ} \mathrm{C}$ for $3 \mathrm{~min}, 35$ cycles of $98^{\circ} \mathrm{C}$ for $30 \mathrm{~s}, 65^{\circ} \mathrm{C}$ for $30 \mathrm{~s}, 72^{\circ} \mathrm{C}$ for $1.5 \mathrm{~min}$ and final extension at $72^{\circ} \mathrm{C}$ for $10 \mathrm{~min}$. The PCR products were checked for size on $1 \%$ agarose gels with ethidium bromide. Standard markers for DGGE were generated from our clone libraries by amplification from miniprepped DNA. The total amount of DNA amplified was measured by band intensity, and then the relative intensities of the samples were calculated. A $6 \%$ polyacrylamide gel was run with a denaturant gradient of 35 to $55 \%$ at $45 \mathrm{~V}$ for $17 \mathrm{~h}$ using the DCodeTM Universal Mutation Detection System (BioRad Laboratories). Five $\mu \mathrm{l}$ of PCR product was loaded into each well. The gel was stained with SYBR Gold (Invitrogen, cat. no. S-11494) for $30 \mathrm{~min}$ and then photographed with a Kodak imaging system (Carestream Health).

We analyzed the distribution patterns of DGGE fragment types using UniFrac based on band patterns and intensity. Band intensity was measured with Kodak molecular imaging software (Carestream Health). The intensity of each band was normalized by the amount of PCR product in that sample. For UniFrac input, we used a star tree and a text file with haplotype abundance levels mapped to environmental data, in which gel positions and band intensity were used as haplotype identity and abundance, respectively.

\section{RESULTS}

\section{Environmental variation}

All stations showed some degree of vertical density stratification driven primarily by freshwater inputs to the surface, as is typical for summer in LIS (Peterson 1986). The strongest stratification was found at Stn 1, where freshwater from the Connecticut River was lay- 

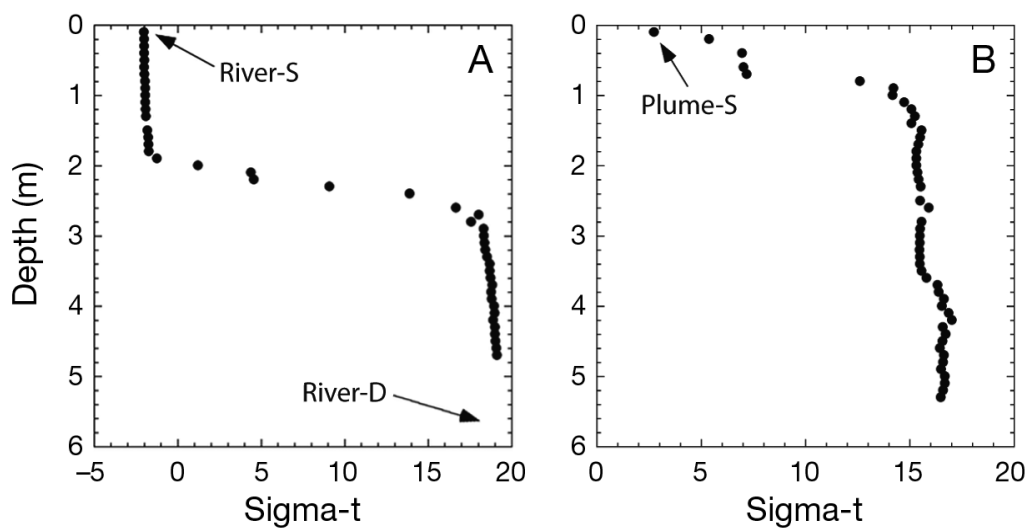

\section{Haplotype distributions}

We sequenced a total of 270 and 372 clones of SSU rDNA from 9 environmental samples using 2 primer sets, OCSP-A and OCSP-B (Oligotrichia and Choreotrichia Specific Primer sets A and B from Doherty et al. 2007, respectively). These primers were assembled with $99 \%$ similarity after a few poor quality or potentially chimeric sequences were removed. With the resulting 263 and 365 sequences, respectively, we detected 47 haplotypes with OCSP-A and 54 haplotypes with OCSP-B (Tables 3 and S1 \& S2 in the supplement at www.int-res.com/ articles/suppl/a064p051_supp.pdf). Of these, 5 and 12 haplotypes were identical to published sequences, respectively (Tables S1 \& S2 in the supplement). Rank abundance curves illustrate the relatively small number of abundant haplotypes among many rare haplotypes and the less steep slope of the OCSP-A curve reveals more common haplotypes compared to OCSP-B (Fig. 3).

For comparisons between the 2 libraries and among samples, we divided the haplotypes into 2 classes: those containing 10 or more sequences were arbitrarily defined as 'common haplotypes' and those with fewer than 10 sequences as 'rare haplotypes'. By this definition, 10 of the 47 OCSP-A haplotypes were common, as were 7 of the 54 produced by OCSP-B. Across all samples, common haplotypes were about 75 and $71 \%$ of the total sequenced clones from primer sets OCSP-A and OCSP-B, respectively. Singletons, haplotypes found only once, represent 23 of the 65 rare haplotype clones sequenced from OCSP-A and 33 of the

ered above saline water from offshore (Fig. 2). The deeper water at Stn 1 had higher salinity than that at Stns 2 and 3, likely due to tidal mixing of river and sound water on the shoals outside the river mouth. Surface water became increasingly saline from Stn $1(0$, practical salinity scale) to 2 (6) to 3 (24), whereas Stns 4 to 6 all showed typical offshore salinities (26 to 27 at the surface). Although we saw visual evidence of a front (surface slick) in the area between Stns 5 and 6, the density profiles did not indicate that the station near the shore (Stn 5) was more well-mixed than the one adjacent to the front and farther offshore (Stn 6), as we had anticipated (Fig. 2).
105 rare haplotype clones sequenced from OCSP-B (Tables 3 and S1 \& S2 in the supplement).

Several haplotypes were quite common in the sequence libraries, though the pattern differed somewhat between primers. Two oligotrichs, Strombidium biarmatum (AY541685) and Strombidium sp. (AY143565), comprised $38 \%$ of all OCSP-B sequences (Table 3). Although $S$. biarmatum was the most abundant haplotype in the OCSP-B library, the most abundant one in OCSP-A was LAK_plu_hap 01, a sequence obtained in the same area during our earlier study (Doherty et al. 2010a), which comprised $15.5 \%$ of all sequences. Determining sequences identical to $S$. biarmatum in the 


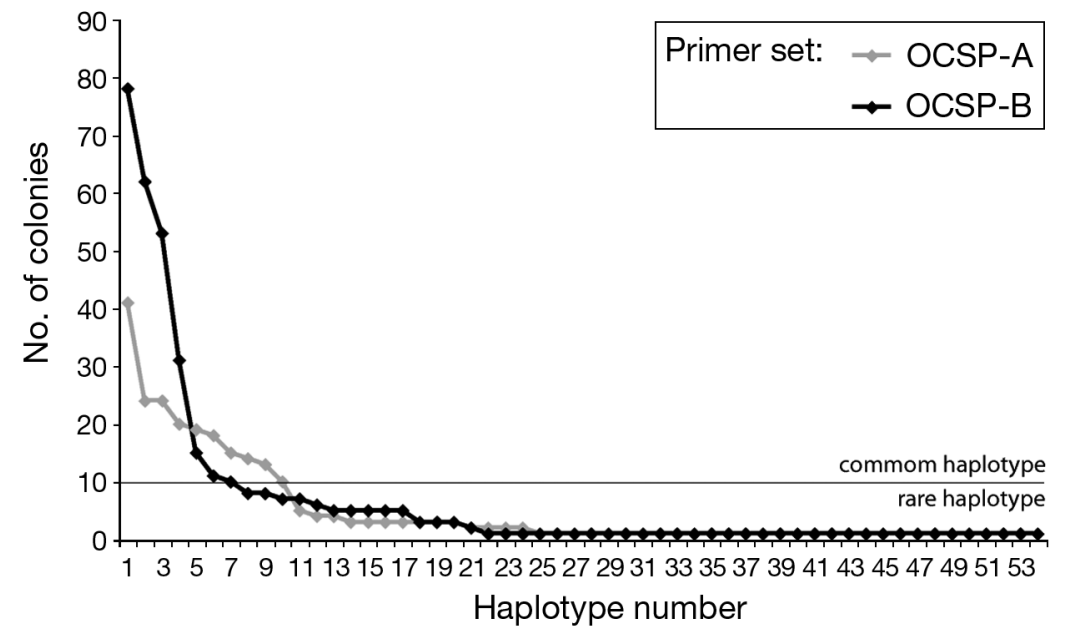

Fig. 3. Rank abundance curves for clone libraries generated from the 2 separate primer sets. Horizontal line indicates arbitrary cutoff between rare ( $<10$ colonies) and common haplotypes for the purpose of comparison the sequence on the $5^{\prime}$ side to compare with our sequences. Using this full length sequence we determined that $S$. biarmatum was the second most abundant haplotype in the OCSP-A data (Table 3). We found a similar difference between primer sets for Strombidium sp.1 (AY143565), which was the second most abundant haplotype in the OCSP$\mathrm{B}$ data and was found at every station. However, for OCSP-A, we found only 2 clones corresponding to Strombidium sp.1 (AY143565), both in the offshore surface sample (Offshore-S) (Table S1 in the supplement). Pelagostrobilidium neptuni (AY541683) was also found in both primer sets (Table 3 ).

Despite the evidence of primer bias indicated by the lack of concordance between the 2 primer sets, there was a

OCSP-A data was difficult inititally because only $50 \mathrm{bp}$ of the published $S$. biarmatum sequence overlapped with the OCSP-A amplicon. We therefore designed a $S$. biarmatum-specific primer and obtained the rest of similar ratio of common and rare haplotypes in the 2 libraries, roughly 70 to $75 \%$ common and 25 to $30 \%$ rare, and the estimates of haplotype diversity for pooled samples were comparable between primer sets

Table 3. Haplotype distribution in different samples according to primer set used: (A) OCSP-A, and (B) OCSP-B. Named haplotypes (100\% identical to Genbank Accession No.) were found in more than one sample and at least 10 clones in total. See Table 1 for descriptions of sampling locations

River-D ${ }^{\mathrm{a}}$ Shore-D ${ }^{\mathrm{a}}$ Front-D ${ }^{\mathrm{a}}$ River-S Plume-S Near_ Offshore- Shore-S Front-S Total Plume-S S

\begin{tabular}{|c|c|c|c|c|c|c|c|c|c|c|}
\hline \multicolumn{11}{|l|}{ (A) OCSP-A } \\
\hline LAK_plu_hap01 & 9 & 1 & 13 & 9 & 8 & & & & 1 & 41 \\
\hline Strombidium biarmatum & & & & & & & 3 & 9 & 12 & 24 \\
\hline hap33 (EF553366) & & & & & & 5 & 12 & 4 & 3 & 24 \\
\hline LAK_plu_hap03 & 10 & & 2 & 5 & 3 & & & & & 20 \\
\hline hap56 (EF553389) & & 2 & & & 3 & 5 & 8 & 1 & & 19 \\
\hline LAK_plu_hap02 & & 1 & & & 1 & 2 & & 7 & 7 & 18 \\
\hline LAK_plu_hap05 & & 1 & 8 & 5 & & & & & 1 & 15 \\
\hline LAK_plu_hap04 & 3 & & 1 & 4 & 4 & 2 & & & & 14 \\
\hline $\begin{array}{l}\text { Pelagostrobilidium neptuni } \\
\text { (AY541683) }\end{array}$ & 8 & & & & 1 & 3 & 1 & & & 13 \\
\hline LAK_plu_hap06 & & & & & & 8 & 2 & & & 10 \\
\hline rare haplotypes & 8 & 9 & 5 & 7 & 12 & 9 & 2 & 10 & 3 & 65 \\
\hline Total & 38 & 14 & 29 & 30 & 32 & 34 & 28 & 31 & 27 & 263 \\
\hline \multicolumn{11}{|l|}{ (B) OCSP-B } \\
\hline $\begin{array}{l}\text { Strombidium biarmatum } \\
\text { (AY541684) }\end{array}$ & & & & & 4 & 11 & 4 & 20 & 39 & 78 \\
\hline Strombidium sp. (AY143565) & & & & 5 & 9 & 9 & 10 & 25 & 4 & 62 \\
\hline hbp1 (EF553391) & & & & 4 & 17 & 17 & 13 & & 2 & 53 \\
\hline LAK_plu_hbp01 & & & & 5 & 16 & & 10 & & & 31 \\
\hline LAK_plu_hbp02 & & & & 2 & 11 & & 2 & & & 15 \\
\hline LAK_plu_hbp03 & & & & 1 & 3 & 1 & 1 & 2 & 3 & 11 \\
\hline $\begin{array}{l}\text { Pelagostrobilidium neptuni } \\
\text { (AY541683) }\end{array}$ & & & & 3 & & 1 & 4 & 2 & & 10 \\
\hline rare haplotypes & & & & 10 & 38 & 18 & 12 & 13 & 14 & 105 \\
\hline Total & & & & 30 & 98 & 57 & 56 & 62 & 62 & 365 \\
\hline
\end{tabular}

${ }^{a}$ OCSP-B libraries were not constructed on the deep water samples. Deep water samples were only used in OCSP-A libraries 
Fig. 4. Rarefaction curves generated with EstimateS; error bars are $95 \%$ confidence intervals to the mean. (A) All stations pooled by primer set, (B) separate stations with primer set OCSP-A only, and (C) separate stations with primer set OCSP-B only. Zigzag line in $\mathrm{C}$ indicates scale break on abscissa

(Fig. 4A, Table 4). Together, these data suggest the need for caution in interpreting clone library-based evidence for presence/absence of specific taxa, though not necessarily for broad patterns of diversity.

\section{Haplotype diversity and richness}

We compared haplotype diversity among samples by constructing rarefaction curves (Fig. 4). Rarefaction compares observed richness among samples relative to sampling effort. Most of the rarefaction trajectories did not reach the asymptote, indicating that additional haplotypes were still to be found at most sites (Fig. 4). Based on the lack of overlap in $95 \%$ confidence intervals, the stations and depths appear to vary significantly in observed diversity. The offshore station (Stn 4) differed from the plume, near-plume, and shore stations (Stns 2, 3 and 5, respectively) in OCSP-A, and the plume differed from the shore and frontal stations (Stns 5 and 6) in OCSP-B (Fig. 4B,C). When all data were pooled by primer set, no indication of haplotype saturation was found (Fig. 4A).

Total haplotype richness was estimated by calculating the non-parametric estimator Chao1 in EstimateS version 8.0 (Colwell 2006) (Table 4). This estimator considers the proportion of singletons and doubletons in the total. Among stations, Chao1 estimates yielded a similar pattern to rarefaction curves in both primer sets. The surface water of the plume sample (Stn 2, Plume-S) had the highest estimated richness in both

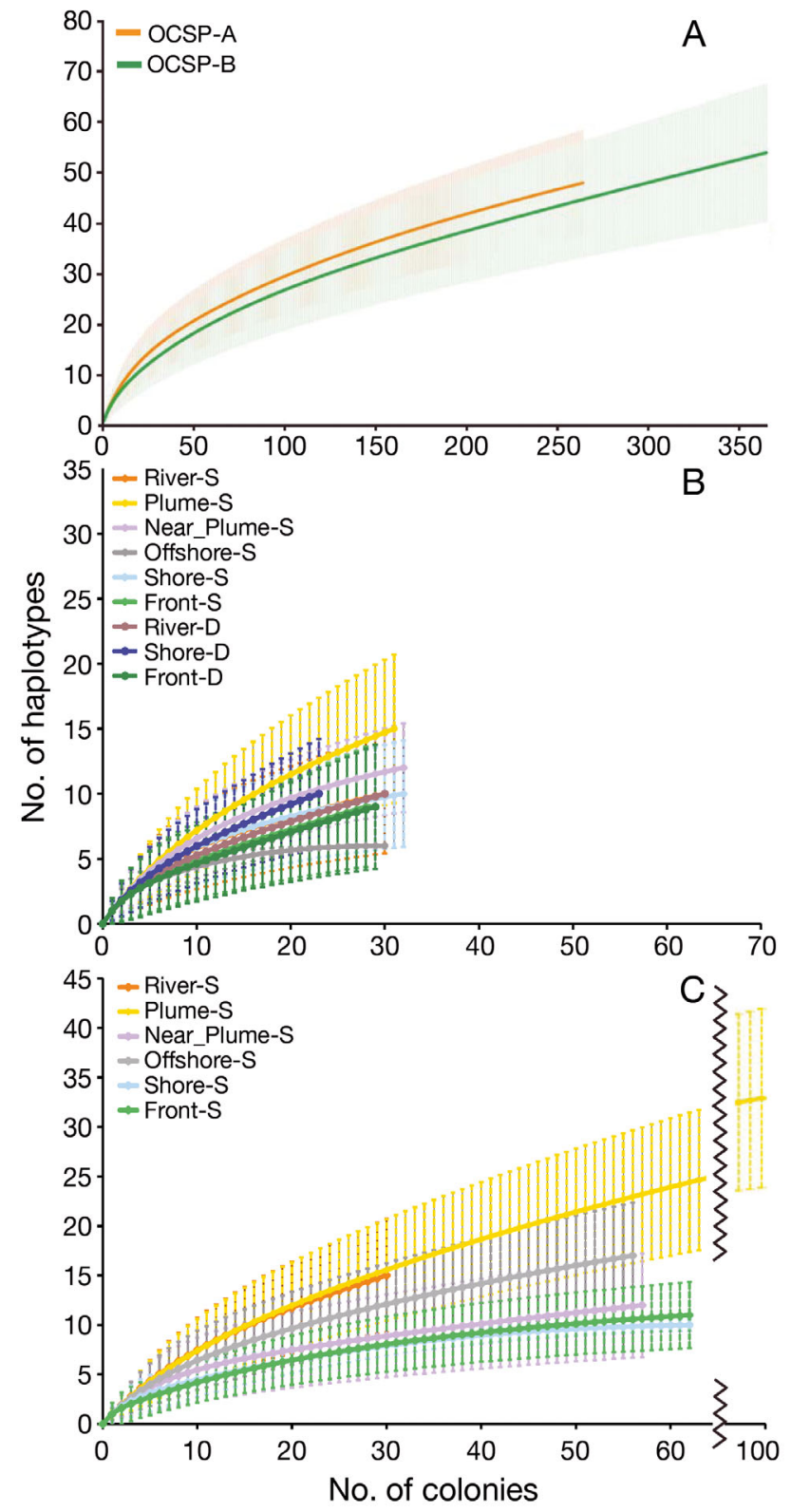

Table 4. Chao1 and Shannon $\left(H^{\prime}\right)$ diversity indices and clone and haplotype diversity determined for 9 samples from 6 stations and grouped according to 2 primer sets. CI: confidence interval; na: not available

\begin{tabular}{|c|c|c|c|c|c|c|c|c|}
\hline \multirow[t]{2}{*}{ Sample } & \multicolumn{2}{|c|}{ — No. of clones - } & \multicolumn{2}{|c|}{ No. of haplotypes } & \multicolumn{2}{|c|}{ Chao1 (95\% CI) } & \multicolumn{2}{|c|}{$\longrightarrow H^{\prime} \longrightarrow$} \\
\hline & OCSP-A & OCSP-B & OCSP-A & OCSP-B & OCSP-A & OCSP-B & OCSP-A & OCSP-B \\
\hline River-S & 30 & 30 & 10 & 15 & $22(11.7-103.8)$ & $35(19.0-118.1)$ & 1.97 & 2.48 \\
\hline Plume-S & 31 & 98 & 15 & 32 & $35(19.0-118.2)$ & $92(48.3-254.4)$ & 2.42 & 2.88 \\
\hline Near_Plume-S & 32 & 57 & 12 & 12 & $16(12.7-37.8)$ & $30(14.5-140.0)$ & 2.21 & 1.97 \\
\hline Offshore-S & 30 & 56 & 6 & 17 & $6(6.0-6.5)$ & 31 (20.0-79.9) & 1.51 & 2.34 \\
\hline Shore-S & 32 & 62 & 10 & 10 & $18(11.0-74.8)$ & $10(10.0-10.3)$ & 2 & 1.64 \\
\hline Front-S & 27 & 62 & 8 & 11 & $24(12.3-77.0)$ & $13(11.3-27.0)$ & 1.66 & 1.45 \\
\hline River-D & 30 & na & 10 & na & $28(12.5-138.0)$ & na & 1.82 & na \\
\hline Shore-D & 22 & na & 9 & na & $19(11.5-63.3)$ & na & 1.94 & na \\
\hline Front-D & 29 & na & 9 & na & $27(11.5-137.0)$ & na & 1.6 & na \\
\hline Total & 263 & 365 & 47 & 54 & $120(70.3-280.6)$ & 599 (153.4-3036.5) & 3.1 & 2.82 \\
\hline
\end{tabular}


primer sets (35 and 92 haplotypes in OCSP-A and OCSP-B, respectively). Although the patterns in richness among stations were similar for both primer sets, Chao1-based estimates of total haplotype richness differed when samples were pooled by primer set (120 and 599 in OCSP-A and OCSP-B, respectively).

The range among stations in Shannon's $H^{\prime}$ diversity index was 1.6 to 2.42 for primer set OCSP-A and 1.45 to 2.88 for primer set OCSP-B (Table 4). The surface river sample (Stn 1, River-S) had the highest value in both primer sets (2.42 in OCSP-A and 2.88 in OCSP-B), whereas the offshore surface (Stn 4, Offshore-S; 1.51) and frontal surface (Stn 6, Front-S; 1.45 ) had the lowest values in primer sets OCSP-A and OCSP-B, respectively. For pooled surface samples, Shannon's $H^{\prime}$ was similar for both primer sets (2.97 and 2.82 in OCSP-A and OCSP-B, respectively; Table 4).

\section{Genealogical analyses}

We constructed SSU rDNA gene trees using sequences of Oligotrichia and Choreotrichia morphospecies from GenBank and all of our sequences (Fig. 5). While some of the haplotypes we found have been observed in previous studies, we also sampled many new haplotypes (42 haplotypes in each primer set), both common and rare (Fig. 5 and Tables S1 \& S2 in the supplement). Both the number of haplotypes and total clones sampled were higher for Choreotrichia than for Oligotrichia in the OCSP-A data. Conversely, for OCSP-B, we sampled more clones from Oligotrichia but a higher number of haplotypes belonged to Choreotrichia (Table 5). This difference reflects the dominance of the oligotrichs Strombidium biarmatum and Strombidium sp. 1 AY143565 in the OCSP-B data.

\section{Community structure based on clone library analyses}

To compare the compositions of haplotype communities across environmental variables, all samples in each primer set were analyzed with the Unifrac program implemented with the RAxML SSU rDNA gene tree. The PCA plot and UPGMA tree, both produced using abundance-weighted UniFrac measurements in primer set OCSP-A, revealed some intriguing patterns (Fig. 6). The 9 samples fell into 3 groups: river and plume surface samples plus 2 of the deeper ones (Cluster I: River-S, Plume-S, River-D and Front-D), 4 of the
Table 5. Distribution of common and rare haplotypes among oligotrichs and choreotrichs in the 2 clone libraries. Haplotypes were considered rare if fewer than 10 colonies were found in a given library

\begin{tabular}{|ccccccc|}
\hline \multirow{2}{*}{$\begin{array}{c}\text { Primer } \\
\text { set }\end{array}$} & $\begin{array}{c}\text { Haplotype } \\
\text { rarity }\end{array}$ & $\begin{array}{c}\text { - Oligotrichia } \\
\text { No. of } \\
\text { haplotypes }\end{array}$ & $\begin{array}{c}\text { No. of } \\
\text { clones }\end{array}$ & \multicolumn{2}{c|}{$\begin{array}{c}\text { Choreotrichia- of } \\
\text { haplotypes }\end{array}$} & $\begin{array}{c}\text { No. of } \\
\text { clones }\end{array}$ \\
\hline OCSP-A & Common & 3 & 58 & 7 & 140 \\
& Rare & 10 & 15 & 27 & 51 \\
OCSP-B & Common & 3 & 151 & 4 & 109 \\
& Rare & 23 & 59 & 24 & 46 \\
\hline
\end{tabular}

surface water samples (Cluster II: Front-S, Shore-S, Near_Plume-S and Offshore-S) and the shore deep water by itself (Cluster III: Shore-D). All clusters were grouped with full jacknife support in hierarchical clustering analysis (Fig. 6B). Cluster II had 2 sub-clusters with high jacknife support: Cluster IIA (Front-S and Shore-S) and IIB (Near_Plume-S and Offshore-S) (Fig. 6A,B). The Unifrac analysis of OCSP-B yielded clusters that were less well-supported and did not show the same patterns as those of OCSP-A.

\section{Community structure based on DGGE analyses}

To ensure repeatability, we carried out DGGE on products from replicate PCRs, including under different cycling conditions (Figs. 7 \& 8). Band patterns were consistent between duplicate PCRs from the same water sample, and most of the bands were shared among samples, although the intensities varied (Fig. 7). Similar band patterns were repeatedly obtained in multiple PCRs at 30 to 35 cycles. Based on migration patterns relative to markers of known size, a total of 22 unique bands was found. Most bands were seen in 2 or more samples (Figs. $7 \&$ \&A). These data indicated that abundant haplotypes can be detected repeatedly by DGGE and that these haplotypes tend to be shared across multiple stations, which was consistent with our clone library results (Table 3).

We also analyzed the DGGE data by Unifrac to assess clustering of abundant haplotypes by comparing band presence/absence and intensity across multiple stations and depths (Fig. 8). Because DGGE is unlikely to detect rare haplotypes, this analysis reflects the spatial patterns of common haplotypes in the assemblages. In Unifrac analyses of the DGGE data, clusters overlapped somewhat with those determined using clone libraries

Fig. 5 (opposite and overleaf). Maximum likelihood trees constructed with RAxML from SSU rDNA sequences from (A) primer set OCSP-A and (B) primer set OCSP-B. Sequences from our clone libraries were combined with ones available on GenBank. Qualitative observations about the distributions of different haplotypes (surface vs. deep water, high vs. low salinity) are indicated, along with presence/absence at different stations. Scale bars are (A) 0.05 and (B) 0.1 substitutions per site 
A

\begin{tabular}{|l} 
River-S \\
Plume-S \\
Near_Plume-S \\
Offshore-S \\
Shore-S \\
Front-S \\
River-D \\
Shore-D \\
Front-D
\end{tabular}
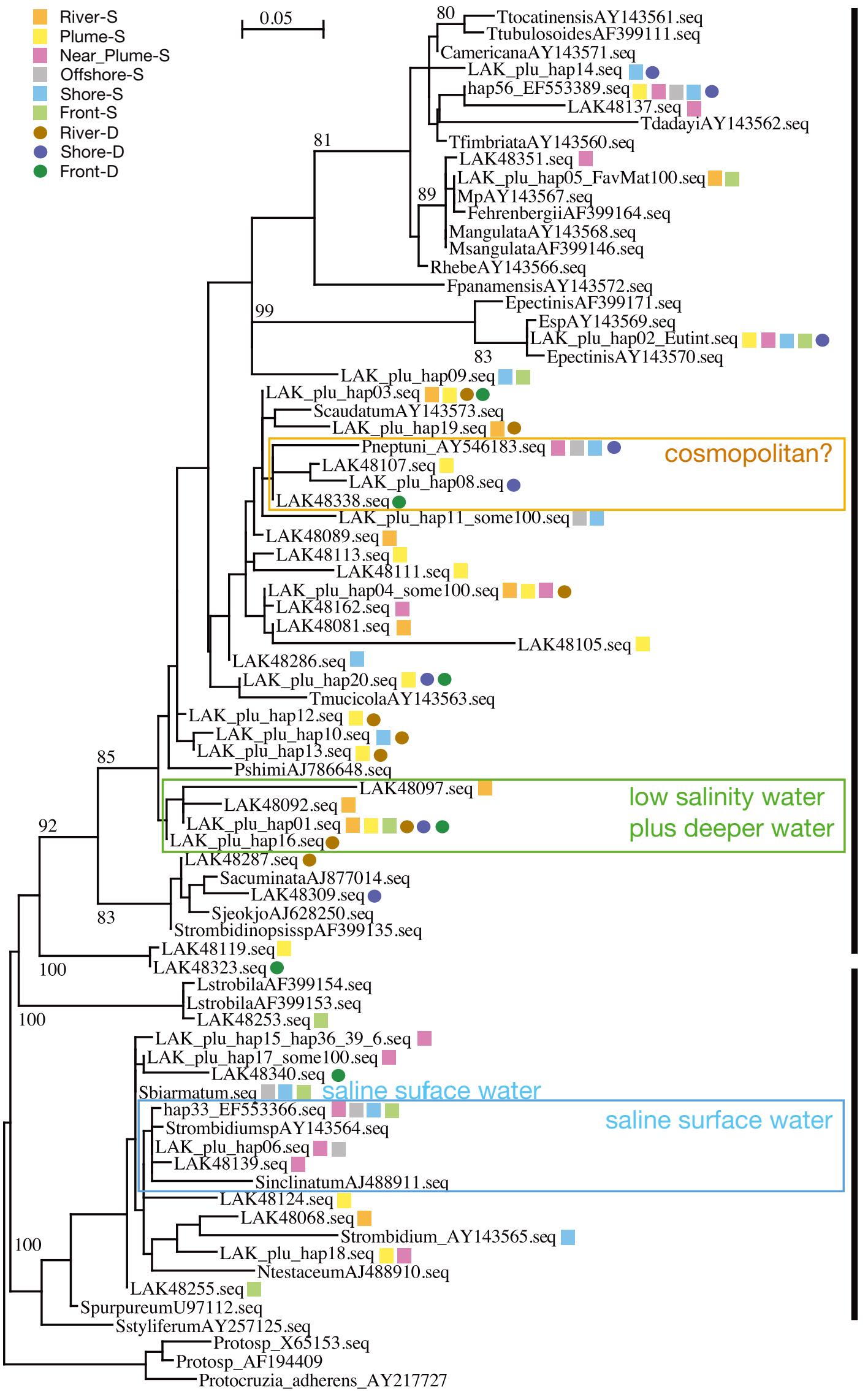

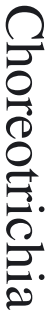

尚. 


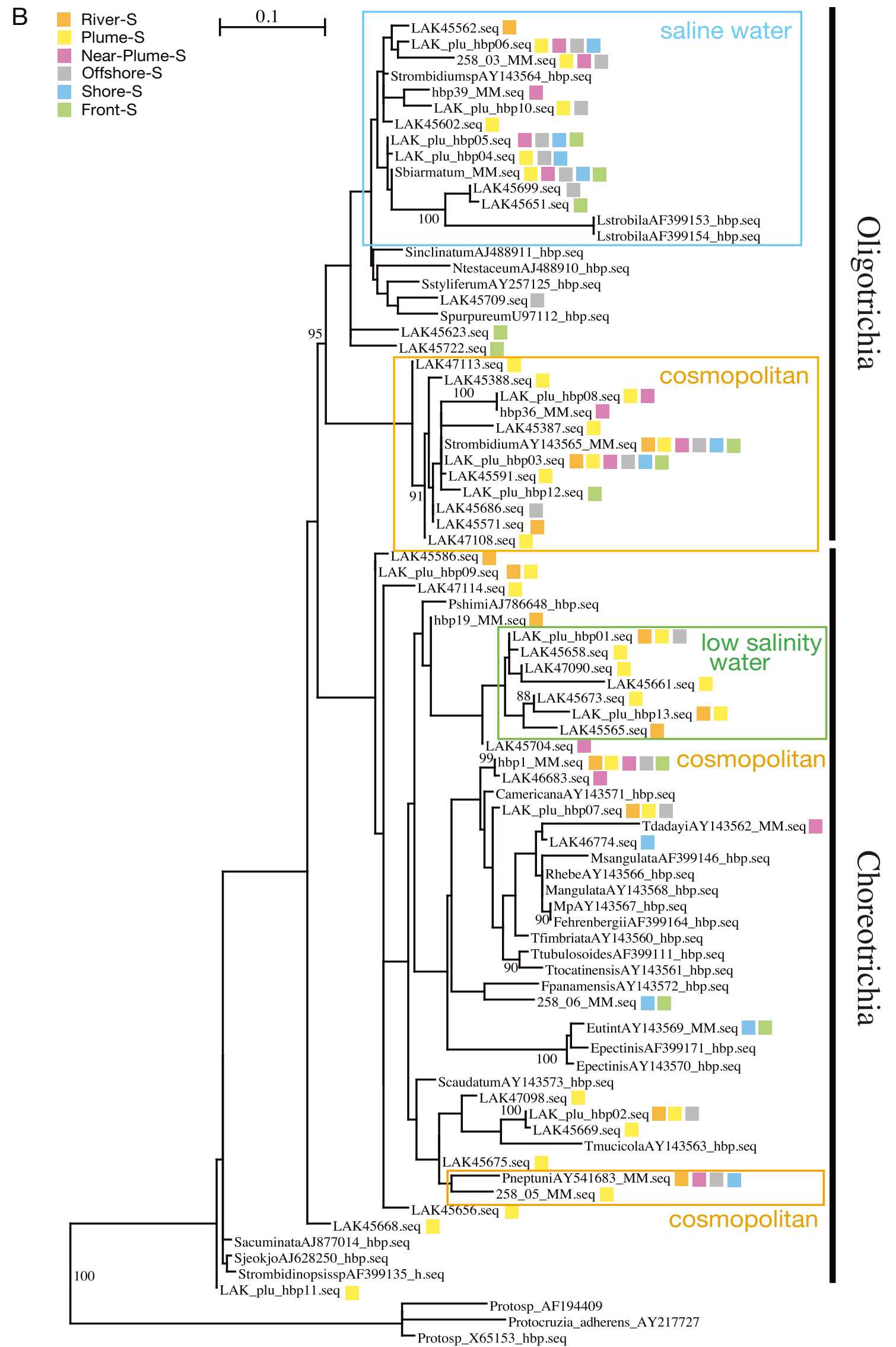

Fig. 5 (continued) 
A

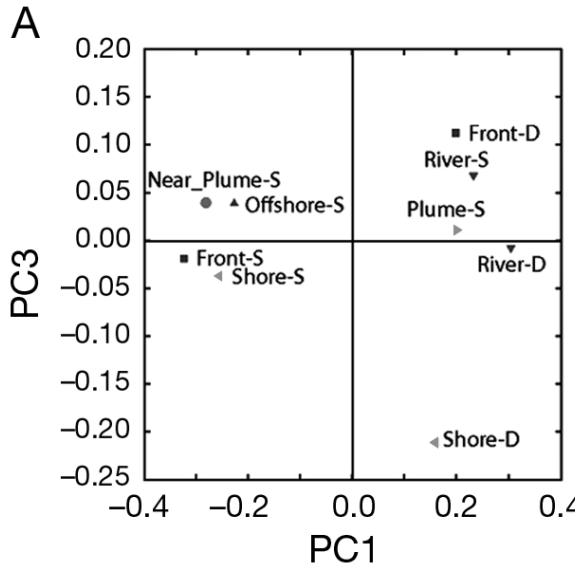

B

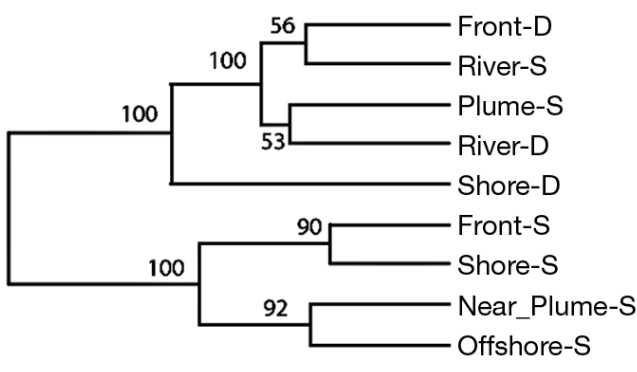

Fig. 6. Clustering of stations based on (A) principal coordinate analysis (PCoA) and (B) unweighted pairgroup method with arithmetic mean (UPGMA). Both analyses were done in UniFrac
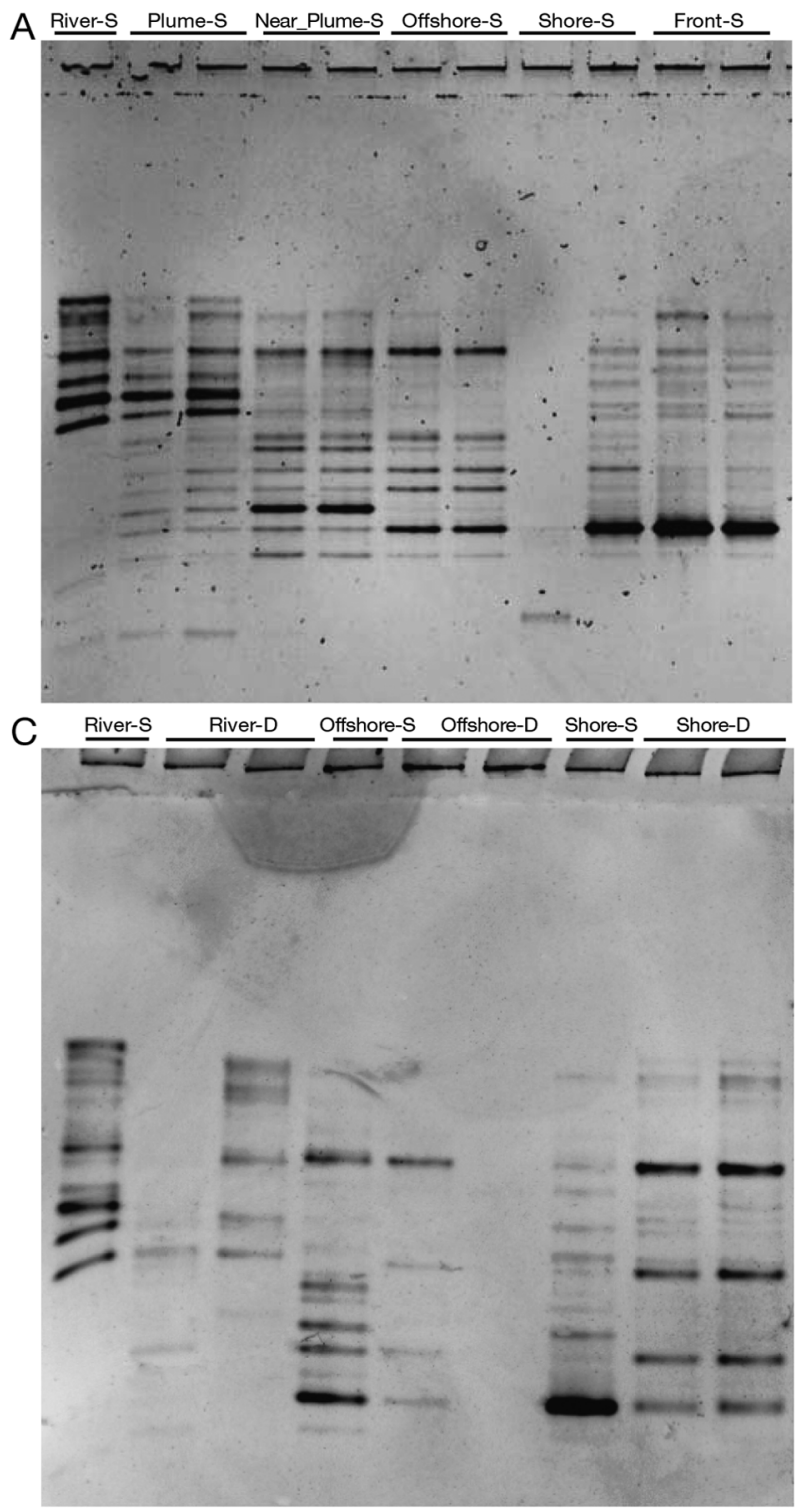

$B$

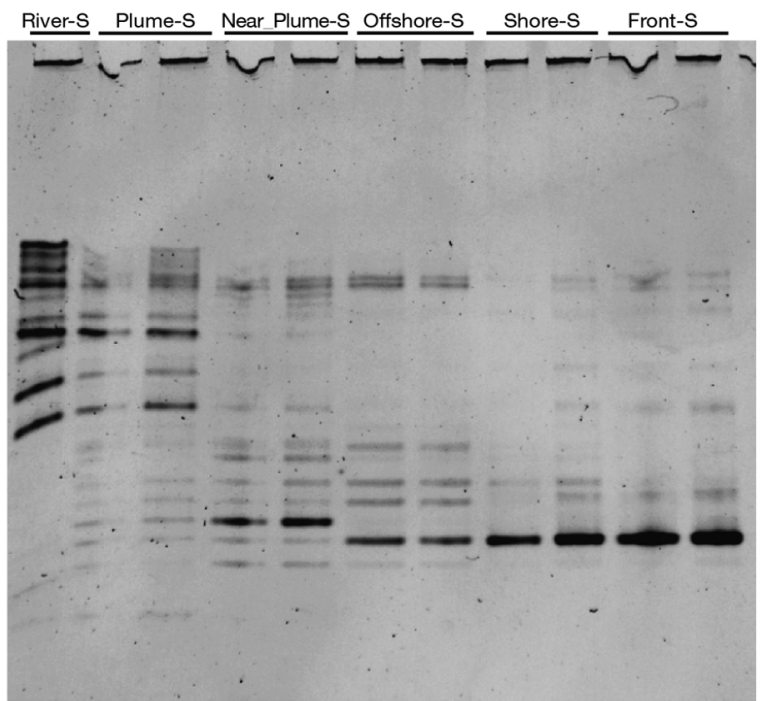

Fig. 7. Denaturing gradient gel electrophoresis (DGGE). Gels show remarkable reproducibility of band patterns for both replicate gels and PCR reactions. (A,B) Replicate gels from surface samples, and (C) surface and deep samples from the same stations. Adjacent lanes with the same label indicate results of duplicate PCR reactions, demonstrating the repeatability of the analysis 


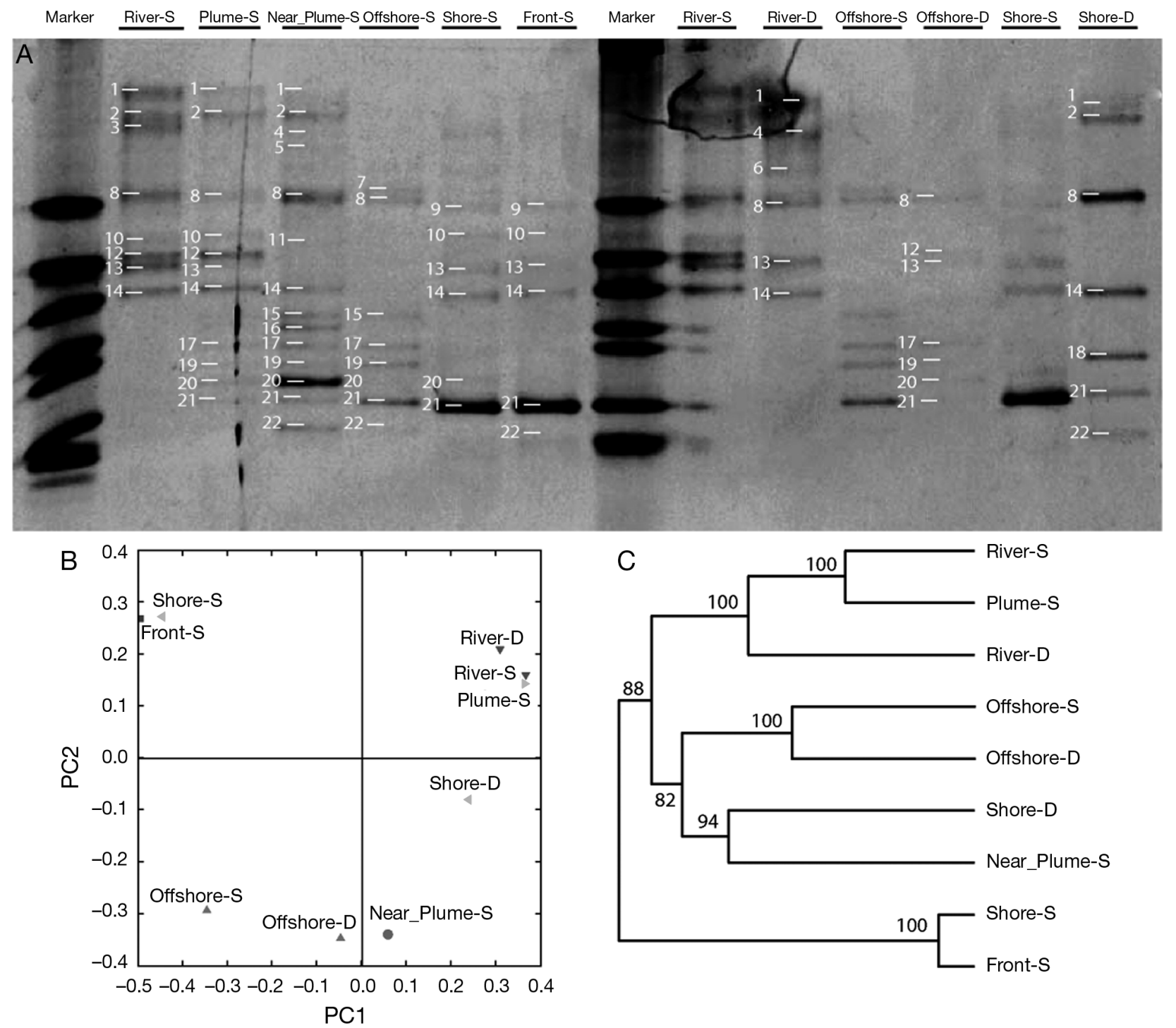

Fig. 8. Analysis of DGGE gels using principal coordinate analysis (PCoA) and hierarchical clustering in UniFrac. (A) Gel showing identified bands, (B) PCoA showing 3 clusters of stations, and (C) UPGMA tree indicating clustering of stations with jackknife support values shown at nodes

generated with OCSP-A. In both analyses, the front and shore surface samples (Front-S and Shore-S) that were close spatially clustered with strong support (Figs. 6 \& 8). Similarly, the surface and deep river waters (River-S and River-D) clustered with the surface plume sample (Plume-S) in both analyses. The front deep sample (Front-D) that clustered within this group in the clone library sample (Fig. 6) was not included in the DGGE analysis as the PCR failed to amplify it reliably with our GC clamped primer. The position of the near-plume surface water (Near_Plume-S) differed between analyses, clustering with the offshore surface water (Offshore-S) in the clone library and the deep shore sample (Shore-D) in the DGGE analyses.

\section{DISCUSSION}

Our DNA-based measurements of diversity produced 3 main observations: (1) coastal planktonic ciliate assemblages consist of a few common haplotypes and numerous rare haplotypes, (2) haplotype richness varied among stations and depths, and (3) community composition differed among samples, but the driving forces behind these differences could not easily be related to common environmental factors, such as temperature, salinity, density stratification and distance from shore. Our results for planktonic ciliates are thus in agreement with the general trend in both protists and bacteria (Sogin et al. 2006, Caron 2009). Most of 
the haplotypes we observed were newly found in this study, and rarefaction curves failed to reach saturation, suggesting that more sampling effort would produce greater estimates of haplotype richness (Figs. 3 \& 4).

Despite sampling considerable haplotype diversity, we captured only a few sequences of morphospecies previously reported in the public databases (e.g. NCBI; Fig. 5). This result is undoubtedly due to the paucity of morphospecies that have been sequenced in these groups. For example, previous investigators of ciliate abundance observed a total of 20 different morphospecies in the genus Tintinnopsis from Long Island Sound (Capriulo \& Carpenter 1983, Capriulo et al. 2002). Of these, only 3 have SSU rDNA sequences published in GenBank and only one of these 3 appeared in our clone libraries (Tintinnopsis dadayi). Thus, many of our sequences may correspond to described morphospecies, but the amount of data available on SSU rDNA sequences in these groups is too small to be of use.

Our total number of haplotypes, 47 for the OCSP-A primer set and 54 for OCSP-B, is similar to the combined species list from Capriulo \& Carpenter (1983) and Capriulo et al. (2002). They found 36 choreotrich and 20 oligotrich morphospecies in samples spanning 4 yr over a spatial scale of $135 \mathrm{~km}$. However, the one morphospecies we found to be ubiquitous and abundant, Strombidium biarmatum, was not described until 2005 (Agatha et al. 2005). This species is rather small $(20 \times 25 \mu \mathrm{m})$, so it may also have been overlooked or assigned to another species in earlier studies.

Our ability to find as many taxa on a single day as earlier studies observed over 4 yr supports the idea that microscopic observations may be missing a large number of the species that are present. However, agreement between morphological species and molecular OTU lists is not necessarily expected (Savin et al. 2004, Doherty et al. 2007). As discussed in Doherty et al. (2007), possible reasons for discordance in molecular and morphological datasets for oligotrich and choreotrich ciliates include bias during amplification or by collections in which distinctive or large described morphospecies are over-represented due to ease of preservation or observation. Also, most morphologically-based examinations of plankton are limited to the most dominant forms because of the difficulty in concentrating and observing rarer ones (Costas et al. 2007), while molecular studies can sample larger volumes of water for rare forms. Furthermore, some haplotypes in clone libraries may represent encysted stages for which no morphological description has been made.

Another reason for the disparity between morphospecies and DNA-based lists is that the criteria for defining taxa are not the same. Morphological identification is based on training and expertise in recogniz- ing the sometimes subtle differences between species but also tends to be conservative in the face of variation among individuals within a species. DNA-based methods are objective but also arbitrary in that some level of molecular difference must be accepted as a boundary for defining OTUs. Because both experimental error and sequence variation within well-established morphospecies is known, a criterion of $100 \%$ identity for defining OTUs is not appropriate. However, the level of variation used to define taxa has not been consistent, ranging from 95 to $99 \%$ in various studies. Caron et al. (2009) and Nebel et al. (2011) suggested that a value of $98 \%$ similarity would provide the best agreement with morphologically-based species distinctions for protists and ciliates, respectively. Yet Nebel et al. (2011) emphasize the difficulty of adhering to any single level of molecular similarity.

We inspected our data, which come from a much narrower group (2 subclasses within a single ciliate class), to determine an appropriate cutoff. We chose $99 \%$ similarity for determining OTUs after comparing results at 98, 99, and $100 \%$ assembly. At $98 \%$, sequences differed from one another at multiple sites with no evidence of recombination among single nucleotide polymorphisms (SNPs). In other words, there is no evidence of recombination among sequences that cluster together at $98 \%$, even for cases for which we had large sample numbers. We are confident that for this group of ciliates and our sequencing methods, $99 \%$ similarity indicates meaningful differences among haplotypes within the samples. The larger issue of whether these differences correspond to the species level is caught up in the difficult question of how one defines microbial eukaryotic species, an issue that cannot be resolved at present (e.g. Schlegel \& Meisterfeld 2003). In sum, while comparison of our OTU data with historic surveys of morphospecies is interesting and informative, whether either approach is the correct one for defining ecologically-distinct entities in the environment is unclear. They are perhaps best viewed as alternative techniques for assessing diversity (Nebel et al. 2011).

As expected, based on our previous study (Doherty et al. 2010a), haplotype diversity varied among samples. The Shannon diversity index $\left(H^{\prime}\right)$ ranged from 1.45 to 2.88 , which was slightly higher than that reported in Doherty et al. (2010a) $\left(H^{\prime}=0.9\right.$ to 2.4$)$. Plume water showed the highest diversity, where the fraction of singletons was high. Samples with the lowest diversity were the offshore (Stn 4) samples in primer set OCSP-A and the shore and front (Stns 5 and 6) water samples in OCSP-B. Similar to the earlier study, haplotype diversity tended to be higher near the river mouth (Doherty et al. 2010a). Morphology-based estimates of tintinnid ciliate diversity in a Mediterranean coastal community across time revealed that 
Table 6. Haplotypes found in more than 10 clones and more than 3 stations, as determined in the present study and Doherty et al. (2010a)

\begin{tabular}{|c|c|c|c|c|c|c|c|c|c|c|c|c|c|c|c|c|c|c|}
\hline \multirow[t]{2}{*}{ Source } & \multirow[b]{2}{*}{ 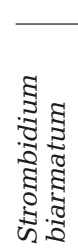 } & \multirow[b]{2}{*}{ 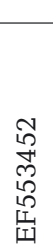 } & \multirow[b]{2}{*}{$\begin{array}{l}\text { on } \\
\text { an } \\
\text { a }\end{array}$} & \multirow[b]{2}{*}{ 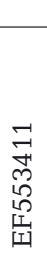 } & \multirow[b]{2}{*}{ 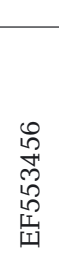 } & \multirow[b]{2}{*}{ 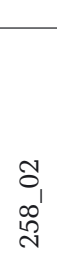 } & \multirow[b]{2}{*}{ 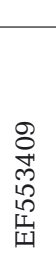 } & \multicolumn{4}{|c|}{ Haplotype name } & \multirow[b]{2}{*}{ 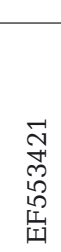 } & \multirow[b]{2}{*}{ 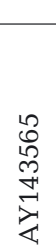 } & \multirow[b]{2}{*}{ 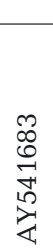 } & \multirow[b]{2}{*}{ 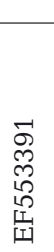 } & \multirow{2}{*}{ 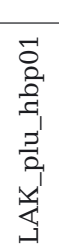 } & \multirow{2}{*}{ 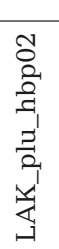 } & \multirow{2}{*}{ 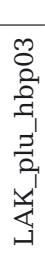 } \\
\hline & & & & & & & & 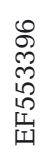 & 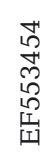 & 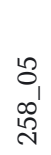 & $\begin{array}{l}\text { ? } \\
\delta_{1} \\
\mathbb{D}_{0}\end{array}$ & & & & & & & \\
\hline Doherty et al. (2010a) & $x$ & $x$ & $x$ & $\mathbf{x}$ & $x$ & $\mathbf{x}$ & $x$ & $\mathbf{x}$ & $x$ & $x$ & $x$ & $x$ & & & & & & \\
\hline Present study & $\mathbf{x}$ & & & & & & & & & & & & $\mathbf{x}$ & $x$ & $x$ & $x$ & $\mathbf{x}$ & $\mathbf{x}$ \\
\hline
\end{tabular}

lower diversity was associated with stratified water columns, whereas diversity increased during spring and autumn when mixing occurred; singletons were observed mainly in spring and autumn (Sitran et al. 2009). In our study, the high diversity river and plume waters were the most heterogeneous in terms of salinity range and the potential for mixing of riverine and marine assemblages. Conversely, the physical environment of the lower diversity deep offshore station (Stn 4) was relatively stable and stratified at the sampling time (August 2008). This finding suggests that ciliate diversity tends to increase in unstable or mixing environments compared to more homogeneous ones. Two species, Strombidium biarmatum and Strombidium sp. AY143565 (referred to as Strombidium sp. 1 in StrüderKypke \& Lynn 2003), comprised a very large portion of the ciliate assemblage in the low diversity shore and front water samples.

To assess community structure, we carried out a clustering analysis of both clone library and DGGE results using Unifrac (Lozupone \& Knight 2005). In both analyses, the surface waters at the front and shore stations (Stns 5 and 6) clustered with strong support, as expected of samples from the same depth at locations in relatively close proximity. However, both analyses also group the river and plume surface waters (low salinity) with the deep river water (high salinity). Because of the large difference in salinity $(>27)$, we had expected to see separate assemblages of riverine and marine haplotypes in surface and deep river samples, respectively. The co-clustering of these samples suggests that the low salinity of the river water is not an environmental barrier to the dominant ciliate species and that motility or vertical mixing is frequent enough over this short vertical distance $(5 \mathrm{~m})$ to result in similar haplotype groupings. The deep frontal sample (Stn 6) also fell within this cluster for the clone library analyses, even though this sample from across the Sound was geographically distant from the river with intervening samples falling in other clusters (Table 1). At the same time, communities from the shore station in deeper water appeared distinct as evidenced by the long branches in Figs. 6B \& 8C, even though this sample was more similar to other high salinity samples (Table 1). This sample was drawn from a shallow region of the Sound and hence may contain a divergent benthic/nepheloid community, contributions from cysts, or both. Together, these clustering analyses indicate that community assemblage is driven by processes more complex than the abiotic factors that we measured (Table 1) and suggest that more detailed depth profiling may yield important insights into community assemblages.

This survey is the second to determine diversity and haplotype distributions of coastal ciliates across environmental gradients in Long Island Sound. We observed a trend of haplotype diversity similar to that of our previous study with richness generally tending

Table 7. Variation in similarity indices for ciliate assemblages sampled on the New England shelf and in Long Island Sound (LIS). The shelf temporal comparison is the average similarity for 3 stations when May assemblages are compared to those from the same station sampled in October. Indices were computed as in Hewson et al. (2006)

\begin{tabular}{|lccccc|}
\hline & $\begin{array}{c}\text { No. of } \\
\text { stations }\end{array}$ & $\begin{array}{c}\text { Maximum spatial } \\
\text { separation }(\mathrm{km})\end{array}$ & $\begin{array}{c}\text { Sorensen } \pm \text { SD } \\
(\mathrm{n})\end{array}$ & $\begin{array}{c}\text { Whittaker } \pm \mathrm{SD} \\
(\mathrm{n})\end{array}$ & Source \\
\hline Shelf, temporal & 3 & 0 & $0.21 \pm 0.12(3)$ & $0.36 \pm 0.23(3)$ & Doherty et al. (2007) \\
Shelf, all & 3 & 530 & $0.21 \pm 0.10(15)$ & $0.29 \pm 0.17(15)$ & Doherty et al. (2007) \\
Shelf, May & 3 & 530 & $0.21 \pm 0.08(3)$ & $0.19 \pm 0.10(3)$ & Doherty et al. (2007) \\
Shelf, Oct & 3 & 530 & $0.16 \pm 0.08(3)$ & $0.27 \pm 0.13$ & Doherty et al. (2007) \\
Coarse-scale LIS & 15 & 23 & $0.40 \pm 0.14(15)$ & $0.38 \pm 0.17(15)$ & Doherty et al. (2010a) \\
Fine-scale LIS & 15 & 2.3 & $0.34 \pm 0.14(15)$ & $0.53 \pm 0.20(15)$ & Present study \\
\hline
\end{tabular}


to be higher around the river mouth (Doherty et al. 2010a). Although clear environmental signals were not associated with changes in community composition among stations and depths, we found some differences in communities near the river mouth and inshore stations compared to the open water samples, indicating that different mechanisms for community assembly in mixed and more stratified waters might exist.

One striking result was the very limited overlap in the lists of common haplotypes found by the present study compared to those found during one conducted in the same area only 14 mo before (Doherty et al. 2010a; Table 6). Although Strombidium biarmatum was one of the dominant haplotypes in both surveys, no other haplotype was observed at more than 3 stations and more than 10 clones in both studies. One morphospecies, Strombidium sp. 1 (AY143565) was found in surface samples from all 6 stations in the present study, even though it was not found at all by Doherty et al. (2010a). This difference might reflect a temporary bloom of Strombidium sp.1 in this area, such as is seen in seasonal blooms of tintinnids in coastal Atlantic waters (Hargraves 1981, Sanders 1987). Hence, our results demonstrate a shift in community composition in the study area between June 2007 and August 2008, which might be a seasonal and/or temporal rotation of rare and common haplotypes. Given the Chao1 estimates of total richness in the hundreds for this study, our ability to observe such shifts from rarity to commonness over time will depend upon application of pyrosequencing or other high throughput efforts in the future.

Using our data and those collected with the same methods by Doherty et al. (2007, 2010a), we evaluated the scales over which ciliate assemblages are coherent using 2 indices of similarity. Sorensen's index is based only on presence/absence data, while Whittaker's index includes relative abundance. Hewson et al. (2006) used a similar approach with prokaryote communities and found strong similarity (Whittaker's index $>0.85$, where 1 would be identical) among samples taken about $2 \mathrm{~km}$ apart in the open ocean. Among samples separated by 10 to $3000 \mathrm{~km}$, similarity declined to a consistent range of 0.38 to 0.47 , leading these authors to suggest that somewhere between 2 and about $50 \mathrm{~km}$ is the typical 'patch size' for bacteria, within which physical processes homogenize communities and change is slow. We compared results from the present study to those obtained earlier in the same area and on the adjacent shelf (Doherty et al. 2007, 2010a). Table 7 gives results of pairwise assemblage comparisons for the shelf, Long Island Sound finescale, and Long Island coarse-scale (present study) observations. Both indices of community similarity produced similar results. On the shelf scale, 3 stations sep- arated by a maximum distance of $530 \mathrm{~km}$ showed low similarity $(0.21$ and 0.29 for Sorensen's and Whittaker's, respectively). Comparisons within stations over time did not produce higher similarity; pairwise comparisons of communities from the same stations sampled in October and May were, on average, 0.21 similar by Sorensen's and 0.36 by Whittaker's. On a smaller scale, the present study compared communities from 15 stations sampled on a single day across a maximum distance of $23 \mathrm{~km}$. Similarity was higher at this scale ( 0.40 and 0.38 for Sorensen's and Whittaker's, respectively). The 15 LIS stations sampled by Doherty et al. (2010a) spanned only $2.3 \mathrm{~km}$, but the level of similarity was about the same as in the present study ( 0.34 and 0.53 for Sorensen's and Whittaker's, respectively). This comparison suggests a modest increase in similarity among ciliate assemblages at shorter spatial scales, but overall the values are low, especially considering that the largest scale considered still represents only $500 \mathrm{~km}$ along a shelf environment that is relatively homogeneous in temperature, salinity, and biotic factors. Undoubtedly, this level of similarity is also in part a result of our inability to sample these assemblages to saturation of the rarefaction curves, and better resolution of the scales over which these communities cohere also awaits more exhaustive sequencing methods.

Acknowledgements. We thank J. Grant, J. Tomaras, and B. Costas for assistance in the field and in the lab. Funding was provided by the National Science Foundation (grants OCE0648713, OCE0648711, and INT0086659), Smith College, and the University of Connecticut.

\section{LITERATURE CITED}

Agatha S, Strüder-Kypke MC, Beran A, Lynn DH (2005) Pelagostrobilidium neptuni (Montagnes and Taylor, 1994) and Strombidium biarmatum nov. spec. (Ciliophora, Oligotrichea): phylogenetic position inferred from morphology, ontogenesis, and gene sequence data. Eur J Protistol 41:65-83

Altschul SF, Madden TL, Schaffer AA, Zhang JH, Zhang Z, Miller W, Lipman DJ (1997) Gapped BLAST and PSIBLAST: a new generation of protein database search programs. Nucleic Acids Res 25:3389-3402

Bowman MJ, Esaias WE, Schnitzer MB (1981) Tidal stirring and the distribution of phytoplankton in Long Island and Block Island Sounds. J Mar Res 39:587-603

Brown MV, Philip GK, Bunge JA, Smith MC and others (2009) Microbial community structure in the North Pacific ocean. ISME J 3:1374-1386

Bulit C, Díaz-Ávalos C, Montagnes DJS (2004) Assessing spatial and temporal patchiness of the autotrophic ciliate Myrionecta rubra: a case study in a coastal lagoon. Mar Ecol Prog Ser 268:55-67

Calbet A, Saiz E (2005) The ciliate-copepod link in marine ecosystems. Aquat Microb Ecol 38:157-167

Capriulo GM, Carpenter EJ (1983) Abundance, species composition and feeding impact of tintinnid micro-zooplank- 
ton in central Long Island Sound. Mar Ecol Prog Ser 10: $277-288$

Capriulo GM, Smith G, Troy R, Wikfors GH, Pellet J, Yarish C (2002) The planktonic food web structure of a temperate zone estuary, and its alteration due to eutrophication. Hydrobiologia 475/476:263-333

> Caron DA (2009) New accomplishments and approaches for assessing protistan diversity and ecology in natural ecosystems. BioScience 59:287-299

Caron DA, Countway PD (2009) Hypotheses on the role of the protistan rare biosphere in a changing world. Aquat Microb Ecol 57:227-238

> Caron DA, Countway PD, Savai P, Gast RJ and others (2009) Defining DNA-based operational taxonomic units for microbial-eukaryote ecology. Appl Environ Microbiol 75: $5797-5808$

Cermeño P, Falkowski PG (2009) Controls on diatom biogeography in the ocean. Science 325:1539-1541

Colwell RK (2006) EstimateS: statistical estimation of species richness and shared species from samples. Available at http://viceroy.eeb.uconn.edu/EstimateS

Costas BA, McManus G, Doherty M, Katz LA (2007) Use of species-specific primers and PCR to measure the distributions of planktonic ciliates in coastal waters. Limnol Oceanogr Methods 5:163-173

Countway PD, Gast RJ, Savai P, Caron DA (2005) Protistan diversity estimates based on 18S rDNA from seawater incubations in the western North Atlantic. J Eukaryot Microbiol 52:95-106

> Countway PD, Gast RJ, Dennett MR, Savai P, Rose JM, Caron DA (2007) Distinct protistan assemblages characterize the euphotic zone and deep sea $(2500 \mathrm{~m}$ ) of the western North Atlantic (Sargasso Sea and Gulf Stream). Environ Microbiol 9:1219-1232

> Darling KF, Wade CM, Stewart IA, Kroon D, Dingle R, Brown AJL (2000) Molecular evidence for genetic mixing of Arctic and Antarctic subpolar populations of planktonic foraminifers. Nature 405:43-47

> Doherty M, Costas BA, McManus GB, Katz LA (2007) Culture-independent assessment of planktonic ciliate diversity in coastal northwest Atlantic waters. Aquat Microb Ecol 48:141-154

> Doherty M, Costas BA, Tamura M, Ritchie ME, McManus GB, Katz LA (2010a) Ciliate diversity and distribution across an environmental and depth gradient in Long Island Sound, USA. Environ Microbiol 12:886-898

> Doherty M, Tamura M, Vriezen JAC, McManus GB, Katz LA (2010b) Diversity of Oligotrichia and Choreotrichia ciliates in coastal marine sediments and in overlying plankton. Appl Environ Microbiol 76:3924-3935

> Dolan JR, Ritchie ME, Ras J (2007) The 'neutral' community structure of planktonic herbivores, tintinnid ciliates of the microzooplankton, across the SE tropical Pacific Ocean. Biogeosciences 4:297-310

> Dolan JR, Ritchie ME, Tunin-Ley A, Pizay MD (2009) Dynamics of core and occasional species in the marine plankton: tintinnid ciliates in the north-west Mediterranean Sea. J Biogeogr 36:887-895

> Finlay BJ (2002) Global dispersal of free-living microbial eukaryote species. Science 296:1061-1063

Foissner W (2006) Biogeography and dispersal of microorganisms: a review emphasizing protists. Acta Protozool 45:111-136

- Gast RJ, Dennett MR, Caron DA (2004) Characterization of protistan assemblages in the Ross Sea, Antarctica, by denaturing gradient gel electrophoresis. Appl Environ Microbiol 70:2028-2037
Gifford DJ (1991) The protozoan-metazoan trophic link in pelagic ecosystems. J Protozool 38:81-86

Hargraves PE (1981) Seasonal variations of tintinnids (Ciliophora, Oligotrichida) in Narragansett Bay, Rhode Island, USA. J Plankton Res 3:81-91

> Hewson I, Steele JA, Capone DG, Fuhrman JA (2006) Temporal and spatial scales of variation in bacterioplankton assemblages of oligotrophic surface waters. Mar Ecol Prog Ser 311:67-77

Lei Y, Xu K, Choi JK, Hong HP, Wickham SA (2009) Community structure and seasonal dynamics of planktonic ciliates along salinity gradients. Eur J Protistol 45:305-319

Long RA, Azam F (2001) Antagonistic interactions among marine pelagic bacteria. Appl Environ Microbiol 67: 4975-4983

> Lozupone C, Knight R (2005) UniFrac: a new phylogenetic method for comparing microbial communities. Appl Environ Microbiol 71:8228-8235

Lozupone C, Hamady M, Knight R (2006) UniFrac — an online tool for comparing microbial community diversity in a phylogenetic context. BMC Bioinformatics 7:371

Lynn DH (2008) The ciliated protozoa: characterization, classification, and guide to the literature, 3rd edn. Springer Verlag, Dordrecht

> Martin DP, Williamson C, Posada D (2005) RDP2: recombination detection and analysis from sequence alignments. Bioinformatics 21:260-262

Montagnes DJS, Poulton AJ, Shammon TM (1999) Mesoscale, finescale and microscale distribution of micro- and nanoplankton in the Irish Sea, with emphasis on ciliates and their prey. Mar Biol 134:167-179

- Nebel M, Pfabel C, Stock A, Dunthorn M, and Stoeck T (2011) Delimiting operational taxonomic units for assessing ciliate environmental diversity using small-subunit rRNA gene sequences. Environ Microbiol Rep 3:154-158

Padidam M, Sawyer S, Fauquet CM (1999) Possible emergence of new geminiviruses by frequent recombination. Virology 265:218-225

> Pedros-Alio C (2006) Marine microbial diversity: Can it be determined? Trends Microbiol 14:257-263

Peterson WT (1986) The effect of seasonal variations in stratification on plankton dynamics in Long Island Sound. In: Bowman MJ, Yentsch CM, Peterson WT (eds) Lecture notes on coastal and estuarine studies, Vol 17. Tidal mixing and plankton dynamics. Springer-Verlag, New York, NY, p 296-320

Pierce RW, Turner JT (1993) Global biogeography of marine tintinnids. Mar Ecol Prog Ser 94:11-26

Posada D (2002) Evaluation of methods for detecting recombination from DNA sequences: empirical data. Mol Biol Evol 19:708-717

Posada D, Crandall KA (2001) Evaluation of methods for detecting recombination from DNA sequences: computer simulations. Proc Natl Acad Sci USA 98:13757-13762

Sanders RW (1987) Tintinnids and other microzooplanktonseasonal distributions and relationships to resources and hydrography in a Maine estuary. J Plankton Res 9:65-77

Savin MC, Gorres JH, Amador JA (2004) Microbial and microfaunal community dynamics in artificial and Lumbricus terrestris (L.) burrows. Soil Sci Soc Am J 68:116-124

Schlegel M, Meisterfeld R (2003) The species problem in protozoa revisited. Eur J Protistol 39:349-355

> Sime-Ngando T, Juniper K, Vézina A (1992) Ciliated protozoan communities over Cobb Seamount: increase in biomass and spatial patchiness. Mar Ecol Prog Ser 89:37-51

> Sitran R, Bergamasco A, Decembrini F, Guglielmo L (2009) Microzooplankton (tintinnid ciliates) diversity: coastal 
community structure and driving mechanisms in the southern Tyrrhenian Sea (Western Mediterranean). J Plankton Res 31:153-170

Smith JM (1992) Analyzing the mosaic structure of genes. J Mol Evol 34:126-129

Sogin ML, Morrison HG, Huber JA, Welch DM and others (2006) Microbial diversity in the deep sea and the underexplored 'rare biosphere'. Proc Natl Acad Sci USA 103: 12115-12120

Stoecker DK, Govoni JJ (1984) Food selection by young larval

Editorial responsibility: Fereidoun Rassoulzadegan, Villefranche-sur-Mer, France gulf menhaden (Brevoortia patronus). Mar Biol 80:299-306 Strüder-Kypke MC, Lynn DH (2003) Sequence analyses of the small subunit rRNA gene confirm the paraphyly of oligotrich ciliates sensu lato and support the monophyly of the subclasses Oligotrichia and Choreotrichia (Ciliophora, Spirotrichea). J Zool (Lond) 260:87-97

Thompson GA, Alder VA (2005) Patterns in tintinnid species composition and abundance in relation to hydrological conditions of the southwestern Atlantic during austral spring. Aquat Microb Ecol 40:85-101

Submitted: November 11, 2010; Accepted: March 29, 2011 Proofs received from author(s): June 27, 2011 